Article

\title{
Comparative Study on the Characteristics of Weissella cibaria CMU and Probiotic Strains for Oral Care
}

\author{
Hye-Jin Jang ${ }^{1}$, Mi-Sun Kang ${ }^{2}$, Sung-Hun $\mathrm{Yi}^{1}{ }^{1}$, Ji-Young Hong ${ }^{1}$ and Sang-Pil Hong ${ }^{1, *}$ \\ 1 Division of Strategic Food Research, Korea Food Research Institute (KFRI), 1201-62 Anyangpangyo-ro, \\ Bundang-gu, Seongnam-si, Gyeonggi-do 13539, Korea; Jang.Hye-jin@kfri.re.kr (H.-J.J.); \\ sunghunyi@kfri.re.kr (S.-H.Y.); Hong.Ji-young@kfri.re.kr (J.-Y.H.) \\ 2 Oradentics Co., Ltd., 3F KM Building 23, Teheran-ro 77-gil, Gangnam-gu, Seoul 06157, Korea; \\ jieenkang@oradentics.com \\ * Correspondence: sphong@kfri.re.kr; Tel.: +82-31-780-9098
}

Academic Editor: Krasimir Vasilev

Received: 4 October 2016; Accepted: 13 December 2016; Published: 20 December 2016

\begin{abstract}
Probiotics have been demonstrated as a new paradigm to substitute antibiotic treatment for dental caries, gingivitis, and chronic periodontitis. The present work was conducted to compare the characteristics of oral care probiotics: Weissella cibaria CMU (Chonnam Medical University) and four commercial probiotic strains. Survival rates under poor oral conditions, acid production, hydrogen peroxide production, as well as inhibition of biofilm formation, coaggregation, antibacterial activity, and inhibition of volatile sulfur compounds were evaluated. The viability of $W$. cibaria CMU was not affected by treatment of $100 \mathrm{mg} / \mathrm{L}$ lysozyme for $90 \mathrm{~min}$ and $1 \mathrm{mM}$ hydrogen peroxide for $6 \mathrm{~h}$. Interestingly, W. cibaria produced less acid and more hydrogen peroxide than the other four probiotics. W. cibaria inhibited biofilm formation by Streptococcus mutans at lower concentrations (S. mutans/CMU = 8) and efficiently coaggregated with Fusobacterium nucleatum. W. cibaria CMU and two commercial probiotics, including Lactobacillus salivarius and Lactobacillus reuteri, showed high antibacterial activities (>97\%) against cariogens (S. mutans and Streptococcus sobrinus), and against periodontopathogens (F. nucleatum and Porphyromonas gingivalis). All of the lactic acid bacterial strains in this study significantly reduced levels of hydrogen sulfide and methyl mercaptan produced by F. nucleatum and P. gingivalis $(p<0.05)$. These results suggest that $W$. cibaria CMU is applicable as an oral care probiotic.
\end{abstract}

Keywords: Weissella cibaria; probiotics; oral care; hydrogen peroxide; biofilm; antibacterial; volatile sulfur compound

\section{Introduction}

More than 700 bacterial species have been detected in the oral cavity [1], and the balance among these bacteria regulates the development of oral diseases such as oral caries, gingivitis and chronic periodontitis [2]. It is generally accepted that the oral microbiota, along with host and diet factors, influences the development of dental caries [3,4]. Streptococcus mutans and Streptococcus sobrinus are example of oral bacteria involved in the early stage of dental caries [5]. The development of dental caries involves of secretion of GTF (glucosyltranferase) by S. mutans, which produces sticky, extracellular dextran-based polysaccharides that allow the bacteria to cohere, forming plaque that causes dental caries [6]. Periodontitis has been associated with the decrease in quality of life due to impairment of masticatory function and attractiveness [7], and has also been implicated in several systematic diseases such as cerebrovascular disease, cardiovascular disease, diabetes and aspiration pneumonia $[8,9]$. The cause of periodontitis is related to bacterial plaques and metabolites, which are 
produced by Gram-negative bacteria, such as Porphyromonas gingivalis and Fusobacterium nucleatum, in the oral cavity [10].

A number of studies on the use of probiotics for the improvement of dental caries, gingivitis, and chronic periodontitis have created a new paradigm for the substitution of existing antibiotic treatments [11-15]. According to the definition by FAO/WHO, probiotics are "live microorganisms, which when administered in adequate amounts, confers a health benefit to the host" [16]. Lactic acid bacteria and Bifidobacteria are the most common types of microbes used as probiotics [16]. Medical conditions that have the potential to be treated with probiotics include diarrhea, gastroenteritis, irritable bowel syndrome, inflammatory bowel disease (Crohn's disease and ulcerative colitis), cancer, depressed immune function, inadequate lactase digestion, infant allergies, failure-to-thrive, hyperlipidemia, hepatic diseases, Helicobacter pylori infection, genitourinary tract infections, and others [17-19]. Regarding studies on probiotics in oral care, Lactobacillus reuteri [11] and Lactobacillus salivarius [15] were reported to prevent dental caries and periodontitis. Recently, Weissella cibaria CMS1 was shown to have preventive effects on biofilm formation [13] and on production of the main sulfur compound in halitosis [12]. Additionally, W. cibaria exhibited antibacterial activity against periodontitis bacteria [12], suggesting its use as a probiotic in oral care products. Weissella is a Gram-positive bacteria within the family Leuconostocaceae [20]. W. cibaria is a lactic acid bacteria that is rod-shaped, non-spore forming, and is heterofermentative, using sugar as a substrate. The morphology of Weissella species varies from spherical or lenticular cells to irregular rods. These species are widely found in saliva or in fermented foods, such as kimchi [21].

In this study, the characteristics of W. cibaria CMU (US 7250162B2), were compared with those of probiotic strains from commercial oral care products based on in vitro analysis, such as antibacterial activity and inhibition of biofilm and sulfur compound formation in addition to other basic analysis.

\section{Results}

\subsection{Resistance against Lysozyme and Hydrogen Peroxide}

\subsubsection{Lysozyme}

Lactic acid bacteria were treated with $100 \mathrm{mg} / \mathrm{L}$ lysozyme solution from 30 to $90 \mathrm{~min}$ as a means of establishing poor survival conditions. Among lactic acid bacteria, the survival ratios of W. cibaria CMU, L. sal and S. sal-1 were not affected by 90 min lysozyme treatment, while S. sal-2 and L. reuteri were reduced by $18.5 \%$ and $3.0 \%$ at $90 \mathrm{~min}$, respectively (Figure $1 \mathrm{a}$ ).

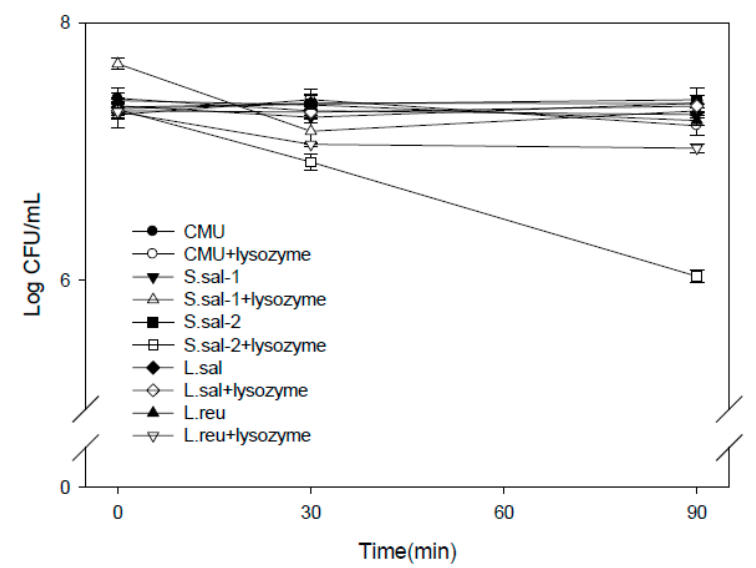

(a)

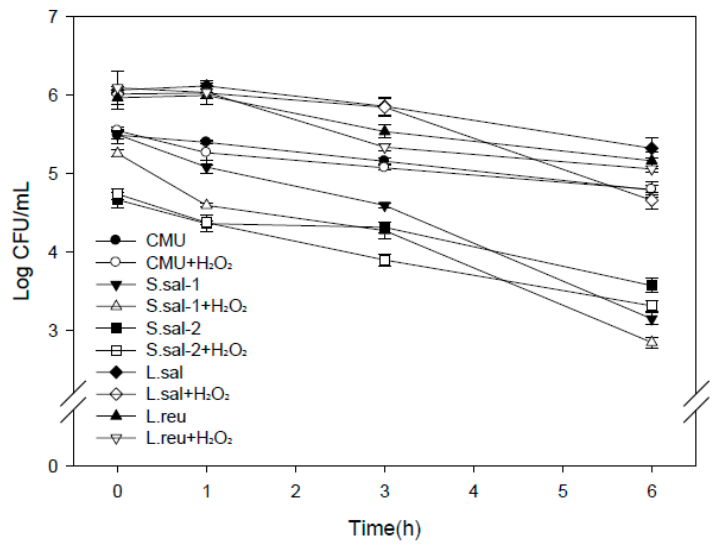

(b)

Figure 1. The survival level of oral probiotic strains after treatment with (a) $0.01 \%$ lysozyme (w/v), and (b) $1 \mathrm{mM}$ hydrogen peroxide. 


\subsubsection{Hydrogen Peroxide}

The survival level for lactic acid bacteria treated with $1 \mathrm{mM} \mathrm{H}_{2} \mathrm{O}_{2}$ for 1, 3, and $6 \mathrm{~h}$ were assessed. The survival of $W$. cibaria CMU and L. reu was not significantly inhibited by hydrogen peroxide. However, S. sal-1, S. sal-2, and L. sal showed a viability ratio of $90.49 \%, 92.83 \%$, and $87.56 \%$ at 6 h, respectively (Figure 1b).

\subsection{Acidogenic Potential}

The acidogenic potential (production of acid value, PAV) of the probiotic strains ranged from 22.28 to 56.47. In particular, W. cibaria CMU showed the highest PAV in carbohydrates: glucose 37.29, fructose 40.09 , sucrose 47.28 , lactose 41.71 , and yeast extract 56.31 (Table 1 ).

Table 1. The ability of oral probiotic strains to produce acid.

\begin{tabular}{ccccccc}
\hline \multirow{2}{*}{ Probiotics } & \multicolumn{5}{c}{ PAV $^{*}$} & \multirow{2}{*}{ F Values } \\
\cline { 2 - 6 } & Glu & Fru & Suc & Lac & YE & \\
\hline CMU & $37.29 \pm 0.09^{\mathrm{a}}$ & $40.09 \pm 0.05^{\mathrm{b}}$ & $47.28 \pm 0.04^{\mathrm{c}}$ & $41.71 \pm 0.19^{\mathrm{d}}$ & $56.31 \pm 0.09^{\mathrm{e}}$ & $15,055.652^{* * *}$ \\
S. sal-1 & $26.08 \pm 0.04^{\mathrm{a}}$ & $26.44 \pm 0.07^{\mathrm{a}}$ & $28.58 \pm 0.15^{\mathrm{b}}$ & $28.74 \pm 0.44^{\mathrm{b}}$ & $51.03 \pm 0.06^{\mathrm{c}}$ & $7563.223^{* * *}$ \\
S. sal-2 & $22.28 \pm 0.03^{\mathrm{a}}$ & $29.62 \pm 0.15^{\mathrm{b}}$ & $25.03 \pm 0.04^{\mathrm{c}}$ & $29.48 \pm 0.01^{\mathrm{d}}$ & $37.13 \pm 0.04^{\mathrm{e}}$ & $17,975.809^{* * *}$ \\
L. sal $^{\text {a }}$ & $31.16 \pm 0.08^{\mathrm{a}}$ & $29.00 \pm 0.01^{\mathrm{b}}$ & $32.78 \pm 0.05^{\mathrm{c}}$ & $32.33 \pm 0.15^{\mathrm{d}}$ & $44.97 \pm 0.01^{\mathrm{e}}$ & $18,270.924^{* * *}$ \\
L. reu & $35.82 \pm 0.19^{\mathrm{a}}$ & $39.16 \pm 0.01^{\mathrm{b}}$ & $36.37 \pm 0.01^{\mathrm{c}}$ & $39.87 \pm 0.10^{\mathrm{d}}$ & $56.47 \pm 0.15^{\mathrm{e}}$ & $16,185.140^{* * *}$ \\
\hline
\end{tabular}

* Production of acid value (PAV) is calculated by multiplying $\mathrm{pH}$ by Log CFU $/ \mathrm{mL}$. ${ }^{* * *} p<0.001$. Glu: glucose,

Fru: fructose, Suc: sucrose, Lac: Lactose, YE: Yeast Extract. ${ }^{a-e}$ Duncan's multiple range comparison.

\subsection{Hydrogen Peroxide Production Potential}

Among lactic acid bacteria in this study, W. cibaria CMU produced the most hydrogen peroxide, followed by L. reu, L. sal, S. sal-1, and S. sal-2 (Figure 2).

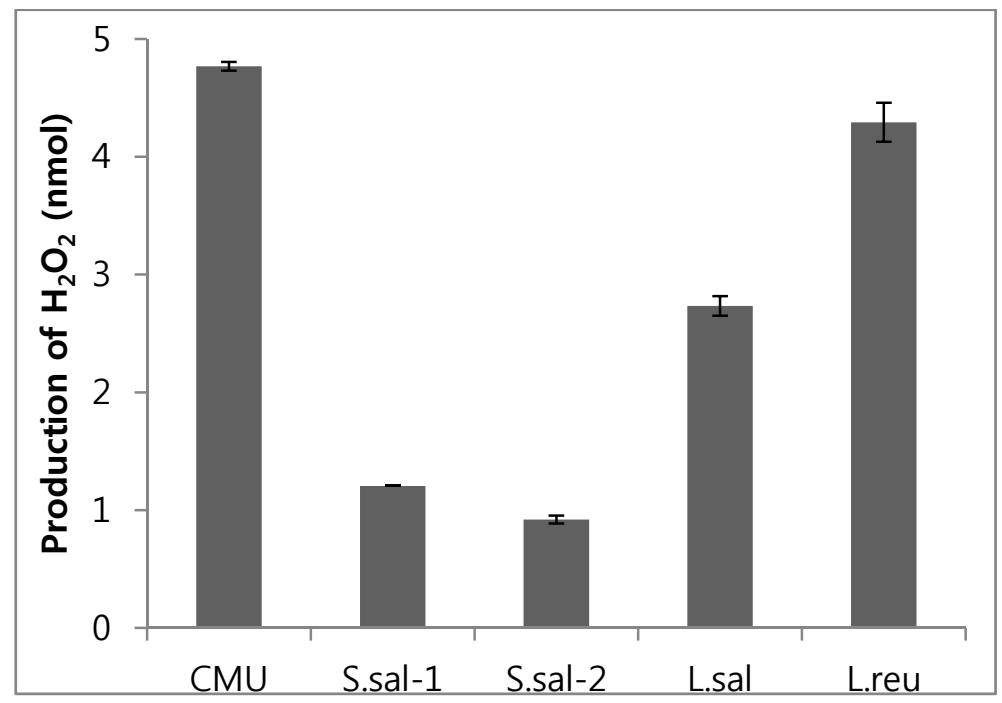

Figure 2. Hydrogen peroxide production activity of probiotics.

\subsection{Inhibition of Biofilm Formation}

As shown in Table 2, W. cibaria CMU and L. sal strongly inhibited biofilm formation in the mixed culture of S. mutans by $94.7 \% \pm 0.3 \%$ and $93.9 \% \pm 0.5 \%$, respectively, followed by L. reu $(85.3 \% \pm 4.0 \%)$, and S. sal-1 $(59.5 \% \pm 2.8 \%)$ at a $1: 1$ ratio. In the case of S. sal-2, there was no significant inhibition of biofilm formation (Table 2). In the dose-dependency assay, W. cibaria CMU showed more than 95\% inhibition through the entire dose range (2:1, 4:1, and 8:1), whereas S. sal-1 and L. sal showed 
dose-dependent inhibition. Furthermore, S. sal-2 and L. reu did not show any inhibition across the range of doses.

Table 2. Dose-dependent effects of oral probiotic strains on the formation of S. mutans biofilms expressed as inhibition level (\%).

\begin{tabular}{ccccc}
\hline \multirow{2}{*}{ Probiotics } & \multicolumn{4}{c}{ S. mutans:Probiotics } \\
\cline { 2 - 5 } & $\mathbf{1 : 1}$ & $\mathbf{2 : 1}$ & $\mathbf{4 : 1}$ & $\mathbf{8 : 1}$ \\
\hline CMU & $94.7 \pm 0.3$ & $96.0 \pm 0.1$ & $96.8 \pm 0.5$ & $95.4 \pm 0.1$ \\
S. sal-1 & $59.5 \pm 2.8$ & $54.6 \pm 3.4$ & $51.5 \pm 2.8$ & $24.1 \pm 2.0$ \\
S. sal-2 & 0 & 0 & 0 & 0 \\
L. sal & $93.9 \pm 0.5$ & $90.7 \pm 2.3$ & $84.6 \pm 4.4$ & $78.8 \pm 4.5$ \\
L. reu & $85.3 \pm 4.0$ & 0 & 0 & 0 \\
\hline
\end{tabular}

\subsection{Antibacterial Activity}

When assessing the antibacterial activity of the probiotics on dental caries bacteria (Table 3) or on periodontal bacteria (Table 4), W. cibaria CMU, L. sal, and L. reu showed higher antibacterial activity as indicated by more than $97 \%$ growth inhibition when compared to the other probiotic strains at a 1:1 ratio. Additionally, L. sal maintained a similar level of antibacterial activity at a 4:1 ratio, except for S. mutans. Also, W. cibaria CMU, L. sal, and L. reu showed antibacterial activity against F. nucleatum and P. gingivalis, as indicated by more than $95 \%$ growth inhibition at a 1:1 ratio. In particular, antibacterial activities of W. cibaria CMU, L. sal, and L. reu against $P$. gingivalis were shown to be more than $98 \%$ at an 8:1 ratio. However, S. sal-1 and S. sal-2 did not have antibacterial activity against dental caries or periodontal bacteria as compared to the other lactic acid bacteria.

Table 3. Dose-dependent effects of oral probiotic culture supernatants on the growth of cariogenic bacteria, F. nucleatum and P. gingivalis, expressed as inhibition level (\%).

\begin{tabular}{|c|c|c|c|c|c|c|c|c|}
\hline Probiotics & \multicolumn{4}{|c|}{ F. nucleatum } & \multicolumn{4}{|c|}{ P. gingivalis } \\
\hline CMU & $97.9 \pm 0.1^{a}$ & $96.0 \pm 0.5^{a}$ & $90.6 \pm 0.8^{a}$ & $36.1 \pm 2.8^{a}$ & $96.9 \pm 0.4^{\mathrm{a}}$ & $99.0 \pm 0.2^{a}$ & $98.8 \pm 0.2^{a}$ & $99.7 \pm 0.3^{a}$ \\
\hline S. sal-2 & $47.0 \pm 1.2^{\mathrm{c}}$ & $15.2 \pm 8.5^{b}$ & $2.0 \pm 6.2^{b}$ & $0.0^{\mathrm{b}}$ & $80.0 \pm 3.4^{b}$ & $36.5 \pm 9.7^{c}$ & $9.9 \pm 0.7^{c}$ & $5.2 \pm 15.6^{c}$ \\
\hline L. sal & $97.4 \pm 0.3^{\mathrm{a}}$ & $94.9 \pm 0.4^{\mathrm{a}}$ & $97.8 \pm 0.4^{\mathrm{c}}$ & $94.3 \pm 0.8^{\mathrm{c}}$ & $96.6 \pm 0.5^{\mathrm{a}}$ & $96.7 \pm 0.6^{\mathrm{a}}$ & $98.2 \pm 0.2^{\mathrm{a}}$ & $98.9 \pm 0.1^{\mathrm{a}}$ \\
\hline
\end{tabular}

Table 4. Dose-dependent effects of oral probiotic culture supernatants on the growth of periodontal bacteria, S mutans and S. sobrinus, expressed as inhibition level (\%).

\begin{tabular}{|c|c|c|c|c|c|c|c|c|}
\hline Probiotics & \multicolumn{4}{|c|}{ F. nucleatum } & \multicolumn{4}{|c|}{ P. gingivalis } \\
\hline CMU & $90.9 \pm 3.4^{\mathrm{a}}$ & $40.1 \pm 8.1^{a}$ & $0.0^{\mathrm{a}}$ & $0.0^{\mathrm{a}}$ & $96.2 \pm 0.3^{a}$ & $81.9 \pm 5.1^{\mathrm{a}}$ & $3.8 \pm 20.2^{a}$ & 0.0 \\
\hline S. sal-2 & $40.4 \pm 4.0^{\mathrm{b}}$ & $19.6 \pm 4.0^{b}$ & $13.2 \pm 5.7^{b}$ & $13.4 \pm 4.2^{\mathrm{b}}$ & $37.1 \pm 6.1^{b}$ & $0.0^{\mathrm{c}}$ & $0.0^{\mathrm{a}}$ & 0.0 \\
\hline L. sal & $96.3 \pm 0.2^{c}$ & $96.0 \pm 1.9^{c}$ & $47.3 \pm 12.5^{c}$ & $0.0^{\mathrm{a}}$ & $96.3 \pm 0.5^{\mathrm{a}}$ & $96.3 \pm 0.5^{\mathrm{d}}$ & $91.6 \pm 2.5^{b}$ & 0.0 \\
\hline
\end{tabular}

*** $p<0.001 .{ }^{\text {a-d }}$ Duncan's multiple range comparison. 


\subsection{Coaggregation}

There was no significant coaggregation between the probiotics and dental caries bacteria or periodontal bacteria. Among probiotics, W. cibaria CMU showed the highest coaggregation with F. nucleatum (81.2\%), followed by S. sal-1 (78.9\%), S. sal-2 (72.7\%), and L. reu (49.6\%), respectively (Table 5).

Table 5. Coaggregation of probiotic strains with cariogenic bacteria or periodontopathic bacteria.

\begin{tabular}{|c|c|c|c|c|}
\hline \multirow{2}{*}{ Probiotics } & \multicolumn{4}{|c|}{ Coaggregation (\%) } \\
\hline & S. mutans & S. sobriuns & F. nucleatum & P. gingivalis \\
\hline CMU & $5.8 \pm 0.6^{a}$ & $0.0^{\mathrm{a}}$ & $81.2 \pm 0.4^{\mathrm{a}}$ & $3.7 \pm 1.2^{\mathrm{a}}$ \\
\hline S. sal-1 & $0.0^{\mathrm{b}}$ & $13.8 \pm 1.3^{b}$ & $78.9 \pm 0.3^{b}$ & $0.0^{\mathrm{b}}$ \\
\hline S. sal-2 & $0.0^{\mathrm{b}}$ & $2.5 \pm 0.2^{c}$ & $72.7 \pm 0.7^{c}$ & $1.5 \pm 0.8^{c}$ \\
\hline L. sal & $0.0^{\mathrm{b}}$ & $0.0^{\mathrm{a}}$ & $0.0^{\mathrm{d}}$ & $0.0^{\mathrm{b}}$ \\
\hline L. reu & $0.0^{\mathrm{b}}$ & $0.0^{\mathrm{a}}$ & $49.6 \pm 0.5^{\mathrm{e}}$ & $0.0^{\mathrm{b}}$ \\
\hline$F$ values & $328.737^{* * *}$ & $309.850 * * *$ & $16,212.931^{* * *}$ & $20.446^{* * *}$ \\
\hline
\end{tabular}

${ }^{* * *} p<0.001 .{ }^{\text {a-e }}$ Duncan's multiple range comparison.

\subsection{Inhibition of VSC Production}

When assay the inhibition of VSC production by the lactic acid bacteria, W. cibaria CMU showed the strongest inhibition as compared to the other lactic acid bacteria. W. cibaria CMU inhibited $\mathrm{H}_{2} \mathrm{~S}$ and $\mathrm{CH}_{3} \mathrm{SH}$ production by F. nucleatum by $97.0 \%$, and by P. gingivalis by $93.9 \%$ (Table 6 ).

Table 6. Inhibitory effects of oral probiotic strains on the production of $\mathrm{H}_{2} \mathrm{~S}$ and $\mathrm{CH}_{3} \mathrm{SH}$ by F. nucleatum and P. gingivalis.

\begin{tabular}{|c|c|c|c|c|c|c|}
\hline \multirow{2}{*}{ Strains } & \multicolumn{3}{|c|}{ VSC (ppb) by F. nucleatum } & \multicolumn{3}{|c|}{ VSC (ppb) by $P$. gingivalis } \\
\hline & $\mathrm{H}_{2} \mathrm{~S}$ & $\mathrm{CH}_{3} \mathrm{SH}$ & Inhibition (\%) & $\mathrm{H}_{2} \mathrm{~S}$ & $\mathrm{CH}_{3} \mathrm{SH}$ & Inhibition (\%) \\
\hline Mono & $25,640 \pm 702$ & $37,225 \pm 782$ & 0 & $12,791 \pm 432$ & $33,553 \pm 876$ & 0 \\
\hline $\mathrm{CMU}$ & $1352 \pm 1272^{\mathrm{a}}$ & $527 \pm 152^{a}$ & 97.0 & $2095 \pm 182^{a}$ & $717 \pm 171^{\mathrm{a}}$ & 93.9 \\
\hline S. sal-1 & $3540 \pm 835^{b}$ & $1532 \pm 500^{b}$ & 91.9 & $1849 \pm 172^{\mathrm{a}}$ & $1423 \pm 78^{b}$ & 92.9 \\
\hline S. sal-2 & $6777 \pm 838^{c}$ & $2030 \pm 246^{b, c}$ & 86.0 & $1531 \pm 82^{b}$ & $1475 \pm 210^{b}$ & 93.5 \\
\hline L. sal & $7081 \pm 290^{c}$ & $2278 \pm 323^{c}$ & 85.1 & $1844 \pm 78^{a}$ & $1335 \pm 130^{b}$ & 93.1 \\
\hline L. reu & $9470 \pm 833^{d}$ & $2242 \pm 505^{c}$ & 81.4 & $3253 \pm 204^{c}$ & $2290 \pm 162^{c}$ & 88.0 \\
\hline$F$ values & $40.340^{* * *}$ & $11.592^{* * *}$ & & $57.013^{* * *}$ & $38.527^{* * *}$ & \\
\hline
\end{tabular}

${ }^{* * *} p<0.001$. ${ }^{\text {a-d }}$ Duncan's multiple range comparison. Volatile sulfur compounds (VSC) which include hydrogen sulfide $\left(\mathrm{H}_{2} \mathrm{~S}\right)$ and methyl mercaptan $\left(\mathrm{CH}_{3} \mathrm{SH}\right)$.

\section{Discussion}

Dental plaque-related diseases (cavities, gingivitis, and periodontitis) has been traditionally controlled by mechanical non-specific removal of plaques. However, a number of novel treatment approaches aim to inhibit the growth of pathogenic bacteria or to remove their toxins.

Recently, antibacterial plant-originated substances [22] or probiotics have been applied as new tools for the improvement of dental health. They have been used to substitute existing antibiotic treatments due to increased resistant bacteria [11-15]. Probiotics not only have antibacterial activity, but they also have inhibitory effects on the reappearance of oral pathogenic bacteria. When choosing the best probiotics for oral health care, it is important to screen probiotics for their viability under poor oral conditions, ability to lower acid production, antibacterial activity, inhibition of biofilm formation, and for oral malodour.

Within saliva, there exists lysozyme and hydrogen peroxide. Lysozyme has an enzymatic activity that cleaves the 1,4-linkage between $\mathrm{N}$-acetylmuramic acid and $\mathrm{N}$-acetylglucosamine in 
the peptidoglycan in bacterial cell wall [23]. Hydrogen peroxide produces hydroxyl radicals that inhibit the growth of pathogenic bacteria. Additionally, hydroxyl radicals can react with nucleic acids to cause damage to genes, and can also increase permeability, limit membrane transportation and denature proteins in cells [24]. Therefore, the resistance capability of lactic acid bacteria to lysozyme or hydrogen peroxide treatment can be used to predict viability in oral conditions.

In the assay for lysozyme resistance, the viabilities of W. cibaria CMU and L. sal were not affected by treatment with $100 \mathrm{mg} / \mathrm{L}$ lysozyme for $90 \mathrm{~min}$. Furthermore, W. cibaria CMU and L. reu showed higher resistance with $1 \mathrm{mM}$ hydrogen peroxide treatment, suggesting that $W$. cibaria CMU is viable under poor oral conditions.

It is known that high lactic acid producing bacteria are not good for oral health because they may cause dental caries [6]. From the calculation of PAV, in which higher values mean lower bacterial acid forming ability, the induction ratio of dental caries from $W$. cibaria CMU was expected to be lower than that of the other lactic acid bacteria in this study. Moreover, lactic acid bacteria can produce organic acids, $\mathrm{CO}_{2}$, diacetyl, lower molecule antimicrobial materials, bacteriocins, and anticohesive materials [17]. Among these products, it is reported that hydrogen peroxide, a representative antibacterial material, induces changes in the bacterial community of the oral cavity and inhibits growth of $F$. nucleatum that causes oral malodor [12]. W. cibaria CMU has shown higher hydrogen peroxide forming ability, as compared with the other lactic acid bacteria. Therefore, it was suggested that $W$. cibaria CMU may have a good ability to reduce oral malodour.

Caries are due to the accumulation of dental plaque (a microbial biofilm) on the tooth surface and at the gingival margin, the vast of majority of which is composed of bacteria [3,4]. As a strategy for the prevention of caries caused by microbial biofilms from S. mutans, probiotics should compete with biofilm forming bacteria and inhibit their growth.

Insoluble glucan is the principal constituent of oral biofilm, and also constitutes a potential site for the formation of carious lesions. The production of glucans from sucrose by GTF is one of the mechanisms underlying the virulence of $S$. mutans [6]. Therefore, the effective suppression of insoluble glucan formation may constitute a viable approach to the prevention of biofilm induced oral diseases such as dental caries.

In this work, W. cibaria CMU and L. sal strongly inhibited biofilm formation by S. mutans, and W. cibaria CMU also showed more than $95 \%$ inhibition across all doses of $S$. mutans used. This results suggest that $W$. cibaria $\mathrm{CMU}$ exhibits functions well as a probiotic. S. sal-2 was previously reported to form BLIS (bacteriocin-like inhibitory substances), an antibacterial material and dextranase, that results in the prevention of the accumulation of dental plaque [25]. However, there was no inhibitory activity against biofilm formation in this study. W. cibaria CMU, L. sal and L. reu also exhibited antibacterial activity for caries and periodontal bacteria similar to previous reports [11,12,15]. Contrary to other studies [14,25], S. sal-1 and S. sal-2 did not exhibit good antibacterial activity. In addition, in the present study, W. cibaria CMU at dose range (S. mutans:CMU = 8:1) strongly inhibited S. mutans biofilm formation by $95.4 \% \pm 0.1 \%$. This result was supported by the report of previous study [13] that dextran (water-soluble glucan) from W. cibaria inhibited the synthesis of water-insoluble glucan by S. mutans, via the conversion of GTF activity from the production of water-insoluble glucan to the production of water-soluble glucan.

Several Weissella, Leuconostoc, Streptococcus, and Lactobacillus spp. can produce dextran. Dextran primarily comprises $\alpha-1,6$-D-glucan and is synthesized by dextransucrase. It is known that dextran can be used as a potential prebiotic for health benefits owing to stimulating the growth of probiotic bacteria such as Bifidobacterium spp. and Lactobacillus acidophilus [26].

In addition, a number of studies have reported that probiotics inhibit a variety of bacteria including P. gingivalis, Treponema denticola, Aggregatibacter actinomycestemcomitans, and Tannerella forsythia $[27,28]$. F. nucleatum is found in the oral cavity, and can serve as a bridge organism, via cohesion and coaggregation, for other bacteria and assist in the inhabitation of the oral cavity [29]. The viability of F. nucleatum is advantageous in the oral cavity as it cannot be easily removed by saliva. Therefore, 
coaggregation with lactic acid bacteria has been suggested to help remove pathogenic bacteria and prevent plaque formation.

In the evaluation of coaggregation between 5 lactic acid bacteria with two dental caries, F. nucleatum and P. gingivalis, and two periodontal bacteria, S. mutans and S. sobrinus, F. nucleatum, W. cibaria CMU showed the highest coaggregation with F. nucleatum, followed by S. sal-1, S. sal-2 and L. reu, but L. sal did not show any coaggregation (Table 5). The above results using $W$. cibaria CMU are in good agreement with a previous study [12].

The benefits of using probiotics for halitosis, oral malodor, have been demonstrated. The main compounds related to halitosis are volatile sulfur compounds produced by Gram-negative bacteria such as F. nucleatum, and P. gingivalis. These volatile sulfur compounds include hydrogen sulfide and methyl mercaptan, both of which comprise about $90 \%$ of the volatile sulfur compound contents in breath [30].

W. cibaria produces lower levels of lactic acids, secretes water soluble glucan and hydrogen peroxide, and thereby prevents halitosis or detal caries [12,13]. In this work, W. cibaria CMU was isolated from saliva obtained from Korean adolescent with good oral health.

As shown in the above results, five probiotics reduced volatile sulfur compounds formed by F. nucleatum and P. gingivalis, and W. cibaria CMU showed the highest activity among them, suggesting that $W$. cibaria CMU may be used as an oral care probiotics.

\section{Materials and Methods}

\subsection{Bacterial Strains and Growth Conditions}

Weissella cibaria CMU (US 7250162B2, CMU), Streptococcus salivarius-1 (S. sal-1), Streptococcus salivarius-2 (S. sal-2), Lactobacillus salivarius (L. sal), Lactobacillus reuteri (L. reu) were used in this study. W. cibaria CMU was obtained from Oradentics Co., Ltd. (Seoul, South Korea), and S. salivarius (S. sal-1, S. sal-2) were isolated from commercial probiotic products using tryptic soy agar (TSA, Difco, Detroit, MI, USA). L. salivarius (L. sal) and L. reuteri (L. reu) were also isolated from commercial probiotics products using De Man, Rogosa, and Sharpe agar (MRS agar, Difco). All bacterial strains were identified through $16 \mathrm{~S}$ rRNA sequence analysis. S. mutans Ingbritt, S. sobrinus B13, F. nucleatum ATCC 10953 and P. gingivalis ATCC33277 were provided by Chonnam National University.

Streptococcus cultures were grown in tryptic soy broth (TSB): Weissella and Lactobacillus cultures were grown aerobically, in MRS broth at $37^{\circ} \mathrm{C}$ for $16 \mathrm{~h}$. F. nucleatum cultures were grown in brain heart infusion broth (BHI broth, Difco) supplemented with $1 \%$ yeast extract (Difco), $0.1 \%$ cysteine (Sigma, St. Louis, MO, USA), $10 \mu \mathrm{m} / \mathrm{mL}$ hemin (Kisan Bio Co., Ltd., Seoul, South Korea), $5 \mu \mathrm{m} / \mathrm{mL}$ menadione (Kisan Bio Co., Ltd., Seoul, South Korea). P. gingivalis cultures were grown anaerobically in TSB supplemented with $0.5 \%$ yeast extract, $0.05 \%$ cysteine, $10 \mu \mathrm{m} / \mathrm{mL}$ hemin, and $5 \mu \mathrm{m} / \mathrm{mL}$ menadione at $37^{\circ} \mathrm{C}$ for two days.

\subsection{Lysozyme Resistance on Bacterial Growth}

Growth inhibition potential of lysozyme (Sigma) for lactic acid bacteria was determined by monitoring survival ratio at TSA or MRS. The pellet was obtained by centrifugation of inoculum of $5 \mathrm{~mL}\left(\mathrm{OD}_{600}=10^{9}\right.$ cells $\left./ \mathrm{mL}\right)$ from $16 \mathrm{~h}$ cultures at $3500 \mathrm{rpm}$ for $10 \mathrm{~min}$ at $4{ }^{\circ} \mathrm{C}$ PBS buffer $(10 \mathrm{~mL})$ containing $100 \mathrm{mg}$ lysozyme/ $\mathrm{L}$ was added to the pellet. The lysozyme treatments were incubated at $37^{\circ} \mathrm{C}$ for 30 and $90 \mathrm{~min}$, and the survival ratios of bacteria were measured by TSA or MRS agar cultures $[31,32]$.

\subsection{Hydrogen Peroxide Resistance on Bacterial Growth}

The growth inhibition potential of hydrogen peroxide (Sigma) on lactic acid bacteria was determined by monitoring the survival ratio in TSA or MRS agar. An inoculum of $0.1 \mathrm{~mL}$ $\left(\mathrm{OD}_{600}=5 \times 10^{8}\right.$ cells $\left./ \mathrm{mL}\right)$ from overnight cultures was incubated in $10 \mathrm{~mL}$ of PBS buffer containing 
$1 \mathrm{mM} \mathrm{H}_{2} \mathrm{O}_{2}$ at $37^{\circ} \mathrm{C}$ for 1,3 , and $6 \mathrm{~h}$, and the survival ratios of bacteria were measured by TSA or MRS agar cultures [33].

\subsection{Acidogenic Potential}

To evaluate the acidogenic potential of lactic acid bacteria, Weissella and Lactobacillus were grown in MRS minimal medium (proteose peptone number 3, beef extract, polysorbate 80, ammnonium citrate, sodium acetate, $\mathrm{MgSO}_{4}, \mathrm{MnSO}_{4}$, dipotassium phosphate) supplemented with $4 \%$ glucose, $4 \%$ fructose, $4 \%$ lactose, $4 \%$ sucrose, or $1.5 \%$ yeast extract, while Streptococcus was grown in TSB minimal medium (pancreatic digest of casein, papaic digest of soybean, sodium chloride, dipotassium phosphate) with the same supplements used for Weissella and Lactobacillus. An inoculum of $0.1 \mathrm{~mL}$ $\left(\mathrm{OD}_{600}=0.05\right)$ from overnight cultures were incubated aerobically at $37^{\circ} \mathrm{C}$ for $24 \mathrm{~h}$, and the $\mathrm{pH}$ and total microaerobes were measured. PAV (production of acid value) was calculated as follows [34]. $\mathrm{PAV}=\mathrm{pH} \times \log \mathrm{CFU} / \mathrm{mL}$.

\subsection{Hydrogen Peroxide Estimation}

Lactic acid bacteria cultures were centrifuged at $3500 \mathrm{rpm}$ for $4 \mathrm{~min}$ at $4{ }^{\circ} \mathrm{C}$, the supernatant was then neutralized to $\mathrm{pH} 7.0$ and filtered through a syringe $(0.45 \mu \mathrm{m})$. The filtrates were assayed based on colorimetry using a hydrogen peroxide assay kit (ab102500, Abcam, Cambridge, MA, USA) [35]. The optical density was read at $570 \mathrm{~nm}$ by a spectrophotometer using $100 \mu \mathrm{L}$ of supernatant placed in 96-well enzyme-linked immunosorbent assay (ELISA) microplate.

\subsection{Inhibition of Biofilm Formation}

S. mutans cultured at $37^{\circ} \mathrm{C}$ overnight was adjusted to $\mathrm{OD}_{600}=0.5\left(\sim 5 \times 10^{8} \mathrm{CFU} / \mathrm{mL}\right)$ and diluted 10 times using TSB with 5\% sucrose (TSB-S). Lactic acid bacteria cultured at $37{ }^{\circ} \mathrm{C}$ overnight were adjusted to $\mathrm{OD}_{600}=0.5\left(\sim 5 \times 10^{7} \mathrm{CFU} / \mathrm{mL}\right)$ and diluted $0.0625,0.125$, and 0.25 times using TSB-S or MRS broth with $5 \%$ sucrose(MRS-S). The $S$. mutans culture $\left(0.1 \mathrm{~mL} ;\left(\sim 5 \times 10^{6} \mathrm{CFU} / \mathrm{mL}\right)\right.$ was inoculated on a 96 well plate, and then, serial dilution of lactic acid bacteria cultures $\left(0.1 \mathrm{~mL} ;\left(\sim 5 \times 10^{6} \mathrm{CFU} / \mathrm{mL}\right.\right.$ to $\sim 6.25 \times 10^{5} \mathrm{CFU} / \mathrm{mL}$ ) were added to each well for inoculation with S. mutans (S. mutans:lactic acid bacteria $=1: 1,2: 1,4: 1,8: 1)$ ). After incubation at $37^{\circ} \mathrm{C}$ for $24 \mathrm{~h}$, media was removed from the wells, and plate wells were washed five times with sterilized distilled water. Plates were air dried for $10 \mathrm{~min}$ and each well was stained with $0.1 \mathrm{~mL}$ of $0.5 \%$ crystal violet solution in water for $15 \mathrm{~min}$. After staining, plates were washed five times with sterilized water. The biofilm formed on the side of each well was dissolved in 99\% ethanol and measured at $595 \mathrm{~nm}$ using a microplate reader (SpectraMax i3 Platform, Molecular Devices, Bismarckring, Austria) [36].

\subsection{Antibacterial Activity}

Lactic acid bacteria cultured aerobically at $37^{\circ} \mathrm{C}$ for $16 \mathrm{~h}$ were centrifuged at $8000 \mathrm{rpm}$ for $30 \mathrm{~min}$ and supernatants were filtered by syringe $(0.45 \mu \mathrm{m})$. Samples were prepared using two, four, and eight times dilutions with TSB or growth medium for periodontal bacteria. Cultures of cariogenic or periodontopathic bacteria were adjusted to $\mathrm{OD}_{600}=0.05\left(\sim 5 \times 10^{7} \mathrm{CFU} / \mathrm{mL}\right)$ using each growth medium. Supernatants of lactic acid bacteria $(0.1 \mathrm{~mL})$ were inoculated on 96 -well plates with cariogenic or periodontopathic bacteria $(0.1 \mathrm{~mL})$. After anaerobic incubation at $37^{\circ} \mathrm{C}$ for $24 \mathrm{~h}$. Each well was measured at $600 \mathrm{~nm}$ using a microplate reader (SpectraMax i3 Platform) [37].

\subsection{Coaggregation Reaction}

Cultures of bacteria were centrifuged at $3500 \mathrm{rpm}$ for $10 \mathrm{~min}$ and the pellets obtained were adjusted to $\mathrm{OD}_{600}=1$ with Cisar's buffer ( $1 \mathrm{mM}$ Tris(hydroxymethyl) aminomethane ( $\left.\mathrm{pH} 8.0\right), 100 \mu \mathrm{M}$ $\mathrm{CaCl}_{2}, 100 \mu \mathrm{M} \mathrm{MgCl}_{2}$, and $0.15 \mathrm{M} \mathrm{NaCl}$ ). Each bacteria or 1:1 mixture of periodontal and lactic acid bacteria was incubated at $37^{\circ} \mathrm{C}$ in a shaking incubator $(\sim 110 \mathrm{rpm})$ for $30 \mathrm{~min}$. After incubation, the 
cultures were left standing for more than $3 \mathrm{~min}$ before $0.5 \mathrm{~mL}$ of the supernatants were measured at $600 \mathrm{~nm}$ using a spectrophotometer (SpectraMax i3 Platform) [38]. The coaggregation was calculated as follows:

$$
\text { Coaggregation }(\%)=\frac{(\mathrm{A} x+\mathrm{A} y) / 2-\mathrm{A}(x+y)}{(\mathrm{A} x+\mathrm{A} y) / 2} \times 100
$$

where $x$ and $y$ represent each of the two strains in the control tubes, and $(x+y)$ the mixture.

\subsection{Inhibition of VSC (Volatile Sulfur Compounds) Production}

Mixtures (1:1) of VSC-producing bacteria $(0.1 \mathrm{~mL})$ and lactic acid bacteria $(0.1 \mathrm{~mL})$, were each adjusted to $\mathrm{OD}_{600}=0.5\left(\sim 5 \times 10^{8} \mathrm{CFU} / \mathrm{mL}\right)$ and were cultured under anaerobic conditions in $15 \mathrm{~mL}$ tubes containing $1 \mathrm{~mL}$ of each growth medium at $37^{\circ} \mathrm{C}$ for $24 \mathrm{~h}$. A sample of the vapor above the cultures was removed using a gas-tight syringe, and $\mathrm{VSC}\left(\mathrm{H}_{2} \mathrm{~S}, \mathrm{CH}_{3} \mathrm{SH}\right)$ production was measured via Oral Chroma (CHM-1, ABILIT, Osaka, Japan) [12].

The inhibition was calculated as follows:

$$
\text { Inhibition }(\%)=\frac{\text { VSC of monoculture }- \text { VSC of mixed culture }}{\text { VSC of monoculture }} \times 100
$$

\subsection{Statistics}

Experiments were replicated three times, and SPSS ver. 12.0 (SPSS Inc., Chicago, IL, USA) was used for statistical analysis. One-way ANOVA was conducted for the significance test between groups, and Duncan's multiple range test was used to determine significant differences between the mean values $(p<0.05)$.

\section{Conclusions}

Probiotics have different benefits in oral care. Among the five probiotics used in this study, W. cibaria CMU showed a strong survival rate under poor oral conditions, and several positive results, including antibacterial activities, production of less acid and more hydrogen peroxide, inhibition of biofilm formation and VSC production, and efficient coaggregation. These results suggest that W. cibaria CMU is applicable as a novel oral care probiotic. Further studies are needed to elucidate its potential for use in the treatment of oral diseases.

Acknowledgments: This research was supported by KFRI (Korea Food Research Institute).

Author Contributions: For research articles with several authors, a short paragraph specifying their individual contributions must be provided. The following statements should be used "Mi-Sun Kang and Sang-Pil Hong conceived and designed the experiments; Hye-Jin Jang and Ji-Young Hong performed the experiments; Sung-Hun Yi analyzed the data; Hye-Jin Jang and Mi-Sun Kang contributed reagents/materials/analysis tools; Mi-Sun Kang and Sang-Pil Hong wrote the paper." Authorship must be limited to those who have contributed substantially to the work reported.

Conflicts of Interest: The authors declare no conflict of interest.

\section{References}

1. Aas, J.A.; Paster, B.J.; Stokes, L.N.; Olsen, I.; Dewhirst, F.E. Defining the normal bacterial flora of the oral cavity. J. Clin. Microbiol. 2005, 43, 5721-5732. [CrossRef] [PubMed]

2. Do, T.; Devine, D.; Marsh, P.D. Oral biofilms: Molecular analysis, challenges, and future prospects in dental diagnostics. Clin. Cosmet. Investig. Dent. 2013, 5, 11-19. [PubMed]

3. Signoretto, C.; Bianchi, F.; Burlacchini, G.; Sivieri, F.; Spratt, D.; Canepari, P. Drinking habits are associated with changes in the dental plaque microbial community. J. Clin. Microbiol. 2010, 48, 347-356. [CrossRef] [PubMed]

4. Baehni, P.; Guggenheim, B. Potential of diagnostic microbiology for treatment and prognosis of dental caries and periodontal diseases. Crit. Rev. Oral Biol. Med. 1996, 7, 259-277. [CrossRef] [PubMed] 
5. Loesche, W.; Straffon, L. Longitudinal investigation of the role of Streptococcus mutans in human fissure decay. Infect. Immun. 1979, 26, 498-507. [PubMed]

6. Bowen, W.; Koo, H. Biology of Streptococcus mutans-derived glucosyltransferases: Role in extracellular matrix formation of cariogenic biofilms. Caries Res. 2011, 45, 69-86. [CrossRef] [PubMed]

7. Bae, K.H.; Kim, H.D.; Jung, S.H.; Park, D.Y.; Kim, J.B.; Paik, D.I.; Chung, S.C. Validation of the Korean version of the oral health impact profile among the Korean elderly. Community Dent. Oral Epidemiol. 2007, 35, 73-79. [CrossRef] [PubMed]

8. Williams, R.C.; Barnett, A.; Claffey, N.; Davis, M.; Gadsby, R.; Kellett, M.; Lip, G.Y.; Thackray, S. The potential impact of periodontal disease on general health: A consensus view. Curr. Med. Res. Opin. 2008, 24, 1635-1643. [CrossRef] [PubMed]

9. Humphrey, L.L.; Fu, R.; Buckley, D.I.; Freeman, M.; Helfand, M. Periodontal disease and coronary heart disease incidence: A systematic review and meta-analysis. J. Gen. Intern. Med. 2008, 23, 2079-2086. [CrossRef] [PubMed]

10. Haffajee, A.D.; Socransky, S.S. Microbial etiological agents of destructive periodontal diseases. Periodontology 2000 1994, 5, 78-111. [CrossRef] [PubMed]

11. Nikawa, H.; Makihira, S.; Fukushima, H.; Nishimura, H.; Ozaki, Y.; Ishida, K.; Darmawan, S.; Hamada, T.; Hara, K.; Matsumoto, A. Lactobacillus reuteri in bovine milk fermented decreases the oral carriage of mutans streptococci. Int. J. Food Microbiol. 2004, 95, 219-223. [CrossRef] [PubMed]

12. Kang, M.S.; Kim, B.G.; Chung, J.; Lee, H.C.; Oh, J.S. Inhibitory effect of Weissella cibaria isolates on the production of volatile sulphur compounds. J. Clin. Periodontol. 2006, 33, 226-232. [CrossRef] [PubMed]

13. Kang, M.-S.; Chung, J.; Kim, S.-M.; Yang, K.-H.; Oh, J.-S. Effect of Weissella cibaria isolates on the formation of Streptococcus mutans biofilm. Caries Res. 2006, 40, 418-425. [CrossRef] [PubMed]

14. Burton, J.; Chilcott, C.; Tagg, J. The rationale and potential for the reduction of oral malodour using Streptococcus salivarius probiotics. Oral Dis. 2005, 11, 29-31. [CrossRef] [PubMed]

15. Ishikawa, H.; Aiba, Y.; Nakanishi, M.; Oh-hashi, Y.; Koga, Y. Suppression of Periodontal Pathogenic Bacteria in the Saliva of Humans by the Administration of Lactobacillus salivarius TI2711. J. Jpn. Soc. Periondontol. 2003, 45, 105-112. [CrossRef]

16. Kopp-Hoolihan, L. Prophylactic and therapeutic uses of probiotics: A review. J. Am. Diet. Assoc. 2001, 101, 229-241. [CrossRef]

17. Brown, A.C.; Valiere, A. Probiotics and medical nutrition therapy. Nutr. Clin. Care 2004, 7, 56-68. [PubMed]

18. Isolauri, E.; Sütas, Y.; Kankaanpää, P.; Arvilommi, H.; Salminen, S. Probiotics: Effects on immunity. Am. J. Clin. Nutr. 2001, 73, 444s-450s. [CrossRef] [PubMed]

19. Parvez, S.; Malik, K.; Ah Kang, S.; Kim, H.Y. Probiotics and their fermented food products are beneficial for health. J. Appl. Microbiol. 2006, 100, 1171-1185. [CrossRef] [PubMed]

20. Bjorkroth, K.J.; Schillinger, U.; Geisen, R.; Weiss, N.; Hoste, B.; Holzapfel, W.H.; Korkeala, H.J.; Vandamme, P. Taxonomic study of Weissella confusa and description of Weissella cibaria sp. nov. detected in food and clinical samples. Int. J. Syst. Evolut. Microbiol. 2002, 52, 141-148. [CrossRef] [PubMed]

21. Lee, K.W.; Park, J.-Y.; Chun, J.-Y.; Han, N.-S.; Kim, J.-H. Importance of Weissella species during kimchi fermentation and future works. Korean J. Microbiol. Biotechnol. 2010, 38, 341-348.

22. Wu, C.D.; Darout, I.; Skaug, N. Chewing sticks: Timeless natural toothbrushes for oral cleansing. J. Periodontal Res. 2001, 36, 275-284. [CrossRef] [PubMed]

23. Callewaert, L.; Michiels, C.W. Lysozymes in the animal kingdom. J. Biosci. 2010, 35, 127-160. [CrossRef] [PubMed]

24. Thomas, E.L. Myeloperoxidase-hydrogen peroxide-chloride antimicrobial system: Effect of exogenous amines on antibacterial action against Escherichia coli. Infect. Immun. 1979, 25, 110-116. [PubMed]

25. Burton, J.P.; Wescombe, P.A.; Macklaim, J.M.; Chai, M.H.; MacDonald, K.; Hale, J.D.; Tagg, J.; Reid, G.; Gloor, G.B.; Cadieux, P.A. Persistence of the oral probiotic Streptococcus salivarius M18 is dose dependent and megaplasmid transfer can augment their bacteriocin production and adhesion characteristics. PLoS ONE 2013, 8, e65991. [CrossRef] [PubMed]

26. Tingirikari, J.M.; Kothari, D.; Goyal, A. Superior prebiotic and physicochemical properties of novel dextran from Weissella cibaria JAG8 for potential food applications. Food Funct. 2014, 5, 2324-2330. [CrossRef] [PubMed] 
27. Kõll-Klais, P.; Mändar, R.; Leibur, E.; Marcotte, H.; Hammarström, L.; Mikelsaar, M. Oral lactobacilli in chronic periodontitis and periodontal health: Species composition and antimicrobial activity. Oral Microbiol. Immunol. 2005, 20, 354-361. [CrossRef] [PubMed]

28. Krasse, P.; Carlsson, B.; Dahl, C.; Paulsson, A.; Nilsson, A.; Sinkiewicz, G. Decreased gum bleeding and reduced gingivitis by the probiotic Lactobacillus reuteri. Swed. Dent. J. 2005, 30, 55-60.

29. Kolenbrander, P.E. Oral microbial communities: Biofilms, interactions, and genetic systems 1. Annu. Rev. Microbiol. 2000, 54, 413-437. [CrossRef] [PubMed]

30. Schmidt, N.F.; Missan, S.R.; Tarbet, W.J.; Cooper, A.D. The correlation between organoleptic mouth-odor ratings and levels of volatile sulfur compounds. Oral Surg. Oral Med. Oral Pathol. 1978, 45, 560-567. [CrossRef]

31. Iacono, V.J.; MacKay, B.J.; DiRienzo, S.; Pollock, J.J. Selective antibacterial properties of lysozyme for oral microorganisms. Infect. Immun. 1980, 29, 623-632. [PubMed]

32. Turchi, B.; Mancini, S.; Fratini, F.; Pedonese, F.; Nuvoloni, R.; Bertelloni, F.; Ebani, V.V.; Cerri, D. Preliminary evaluation of probiotic potential of Lactobacillus plantarum strains isolated from Italian food products. World J. Microbiol. Biotechnol. 2013, 29, 1913-1922. [CrossRef] [PubMed]

33. Sun, J.; Hu, X.-L.; Le, G.-W.; Shi, Y.-H. Inhibition of Fe-induced colon oxidative stress by lactobacilli in mice. World J. Microbiol. Biotechnol. 2013, 29, 209-216. [CrossRef] [PubMed]

34. Bosch, M.; Nart, J.; Audivert, S.; Bonachera, M.A.; Alemany, A.S.; Fuentes, M.C.; Cuné, J. Isolation and characterization of probiotic strains for improving oral health. Arch. Oral Biol. 2012, 57, 539-549. [CrossRef] [PubMed]

35. Viswanathan, K.; Vadivoo, V.; Raj, G.D. Rapid determination of hydrogen peroxide produced by Lactobacillus using enzyme coupled rhodamine isocyanide/calcium phosphate nanoparticles. Biosens. Bioelectron. 2014, 61, 200-208. [CrossRef] [PubMed]

36. Djordjevic, D.; Wiedmann, M.; McLandsborough, L. Microtiter plate assay for assessment of Listeria monocytogenes biofilm formation. Appl. Environ. Microbiol. 2002, 68, 2950-2958. [CrossRef] [PubMed]

37. Kang, M.-S.; Oh, J.-S.; Lee, H.-C.; Lim, H.-S.; Lee, S.-W.; Yang, K.-H.; Choi, N.-K.; Kim, S.-M. Inhibitory effect of Lactobacillus reuteri on periodontopathic and cariogenic bacteria. J. Microbiol. 2011, 49, 193-199. [CrossRef] [PubMed]

38. Cisar, J.; Kolenbrander, P.; McIntire, F. Specificity of coaggregation reactions between human oral streptococci and strains of Actinomyces viscosus or Actinomyces naeslundii. Infect. Immun. 1979, 24, 742-752. [PubMed]

Sample Availability: Samples of W. cibaria CMU, S. sal-1, S. sal-2, L-sal, and L. reu are not available from the authors.

by the authors; licensee MDPI, Basel, Switzerland. This article is an open access article distributed under the terms and conditions of the Creative Commons Attribution (CC-BY) license (http://creativecommons.org/licenses/by/4.0/). 